\title{
Oficinas de artes visuais: empoderamento e desenvolvimento de habilidades sociais para adolescentes em situação de risco social
}

\author{
Visual arts workshops: empowering and development \\ of social skills for adolescents at social risk
}

\author{
Berliete Bolzani, ${ }^{1}$ Maria Georgina Marques Tonello, ${ }^{1}$ Cléria Maria Lobo Bittar ${ }^{1}$
}

'Universidade de Franca, Franca, PR, Brasil.

Recebido em: 26/06/2016 / Aceito em: 22/08/2016 / Publicado em: 30/09/2016

profa.cleriabittar@gmail.com

\section{RESUMO}

Objetivo: desenvolver oficinas de artes visuais com adolescentes em situação de risco social, com ênfase na intervenção grupal, visando a criação de um espaço de troca de experiências, aproximação social e desenvolvimento de habilidades sociais, além de conhecer suas percepções sobre os trabalhos realizados nas oficinas. Método: estudo de natureza qualitativa, observacional e participante. Foram realizadas 30 oficinas uma vez por semana com um grupo de 18 adolescentes, de 11 a 15 anos, de ambos os sexos, assistidos por uma ONG. As atividades foram registradas em diário de campo, bem como os relatos, comentários, percepções e comportamento dos adolescentes, sobre as atividades realizadas e a impressão que estas Ihes causavam. A transcrição destes relatos foi feita posteriormente, mantendo-se a fala original. Resultados: após a realização das oficinas, os adolescentes foram capazes de perceberem a si mesmos com mais assertividade, melhoraram sua autopercepção, foram capazes de identificar suas necessidades, seus limites e terem discernimento sobre o que podiam ou não fazer. Demonstraram maior interesse nos cuidados consigo e com sua aparência pessoal, além de terem modificado sua percepção em relação ao outro. Considerações finais: as oficinas proporcionaram melhora das habilidades sociais, no empoderamento, na autoestima, auxiliando-os a lidarem melhor com as situações do cotidiano. Trata-se de uma estratégia que está em consonância com os princípios da Promoção da Saúde, conforme preconiza a Organização Mundial da Saúde.

Palavras-chave: Educação; Promoção da Saúde; Artes Visuais; Adolescentes em risco social.

\section{ABSTRACT}

Objective: promote visual arts workshops with adolescents at social risk with emphasis on group intervention, aiming the creatoin of a space for exchanging experiences, social approach and development of social skills, as well as know their perceptions about the work done in the workshops. Method: qualitative, observational and participating study. 30 workshops were held once a week with a group of 18 teens (11-15 years) both genders and assisted by an NGO. The activities were recorded in a note field, as well as reports, comments, perceptions and adolescents behavior about the activities done and the impression caused in each one. These reports were transcriped later keeping the original speech. Results: After the end of the workshops the teenagers were able to realize themselves with more assertiveness, have improved their self-perception, were able also to identify their needs, their limits and have discernment about what they can and can't do. They have shown greater interest in them and their personal appearance, besides they have modified their perception in relation to each other. Closing remarks: workshops provided improvemente in social skills, cognitive and emotional; helping participants to cope better with everyday situations. It is a strategy that is in line with the principles of health promotion as advocates by the World Health Organization.

Keywords: Education; Health promotion; Visual Arts; Adolescents at social risk. 


\section{INTRODUÇÃO}

A promoção da saúde tem como uma das estratégias fundamentais defender a saúde como o maior recurso para o desenvolvimento social, econômico e pessoal e fazer com que os determinantes da saúde favoreçam a saúde e a igualdade de oportunidades, por meio de capacitação e da mediação entre diferentes interesses. ${ }^{1,2}$ O protagonismo das ações que visam melhorar as condições de saúde é das comunidades e de outros atores sociais em diferentes espaços que vislumbrem ações que ensejam a produção/promoção da saúde, como os ambientes familiares, as escolas as ONGs - Organizações Não Governamentais.

Sobre o papel das ONGs, acredita-se que estas podem contribuir, tanto para compreensão das diferenças entre o ensino formal e o não formal, bem como auxiliar as políticas públicas que garantam o ensino, a atenção psicossocial a diferentes grupos sociais. ${ }^{3}$

Além dos serviços e ações em saúde, tradicionalmente conhecidos, ações de natureza social, educativa, artística, esportiva, dentre outros, são pensadas como possibilidades de promover as mudanças nos estilos de vida, na adoção de hábitos mais saudáveis que adotem a premissa da promoção da saúde.

Pensando na adolescência como um período de profundas alterações fisiológicas, psíquicas e emocionais e na importância do entorno social para a adoção de hábitos saudáveis, a arte é vislumbrada como uma possibilidade de estratégia de Promoção da Saúde, pois permite autoconhecimento, interação social e o empoderamento. $\mathrm{O}$ empoderamento é uma potente ferramenta conceitual utilizada pela Promoção da Saúde, que define-se pelo aumento da capacidade dos indivíduos para definirem, analisarem e atuarem sobre seus próprios problemas por meio da aquisição de habilidades para responder aos desafios da vida em sociedade. ${ }^{4}$

$\mathrm{Na}$ adolescência, as relações sociais se ampliam; os adolescentes se unem em grupos de interesse e personalidade parecidos, surgem novos esquemas de interpretação de mundo, e todas essas transformações sofrem influência dos fatores ambientais, culturais, sociais e econômicos. A cultura é a chave para se entender esse novo olhar sobre o mundo. É o aprendizado das normas sociais e culturais que imprime características na personalidade do adolescente, a partir de sua relação com a família, à escola e com os outros. ${ }^{5-7}$ Além disso, eles estão sofrendo diretamente influência da sociedade, caracterizada pela informação, lazer, consumo e também pelas tecnologias da comunicação (televisão e internet). Desde cedo, têm contato com mensagem sobre sexo, violência, uso e abuso de drogas e álcool. ${ }^{8}$

A adolescência é, portanto, tanto a "aptidão para crescer", não apenas no sentido físico, mais também psíquico, como para "adoecer", em termos de sofrimento emocional, com as transformações biológicas e mentais que operam nesta faixa da vida. ${ }^{9}$

Segundo relatório da Unicef 7 , este grupo etário está sujeito às situações de risco tal como homicídios, acidentes, suicídios e complicações decorrentes do HIV, além dos danos decorrentes da pobreza, desemprego na família e pouca ou nenhuma escolaridade. A compreensão da vulnerabilidade do adolescente refere-se ao contexto em que vive e as situações a que se expõe.
Dessa forma, essa vulnerabilidade deve ser levada em conta nas decisões de ações de promoção e educação em saúde do adolescente. ${ }^{10}$

Sobre o conceito de vulnerabilidade, Farre ${ }^{11}$ traz importante reflexão quando aponta que para o sucesso com ações em Promoção da Saúde para adolescentes, torna-se necessário redefinir a visão comum, estereotipada e preconceituosa do adolescente como um ser vulnerável, para o que pode estar vulnerável aos riscos, o que significa adotar uma posição que compreende outros fatores sociais que afetam a vida das pessoas, tanto no âmbito individual como no coletivo, como suas crenças, hábitos e atitude pessoais; mas igualmente o acesso à saúde, educação, transporte, políticas públicas, controle social e outros.

Torna-se necessário, portanto, promover ações efetivas e resolutivas de saúde, quanto à qualidade de vida, ao cuidado consigo mesmo e com o meio ambiente, e também em relação às situações afetivas com proximidade e intimidade. É preciso entender também, que a condição de vulnerável não é sinônimo de incapacidade e sim de necessidade de se oferecer condições para que o adolescente adote comportamentos saudáveis a fim, tanto de superar os fatores de risco aos quais estão expostos, como o de melhorar sua autoestima e comportamento.

A arte pode ser utilizada na criação de habilidades sociais e pessoais, pois possibilita o equilíbrio entre o intelecto e as emoções, o que facilita ao adolescente adotar uma atitude mais proativa e reflexiva, além de poder pensar seus valores e comportamentos, em busca de uma (com) vivência mais harmoniosa e equilibrada, o que pode resultar em uma existência com mais bem estar e qualidade de vida. ${ }^{12,13} \mathrm{~A}$ arte propicia uma compreensão profunda das questões sociais, pois solicita a percepção visual, bem como os demais sentidos e é por meio dela que o adolescente compreende a dimensão poética presente em seu meio. ${ }^{14} \mathrm{Na}$ busca do elemento artístico específico do seu fazer, o adolescente depara-se com o equilíbrio, movimento, cor, forma, ritmo e outros elementos das artes visuais.

A arte também possibilita a expressão criativa e inovadora, além da ampliação das possibilidades de expressão dos sentimentos como medos, frustrações, dúvidas, tão comuns nesta faixa etária, facilitando o desenvolvimento intelectual, emocional e o sentido de aquisição da própria liberdade e autonomia.

Ao participar de um projeto de oficinas de artes, o adolescente está envolvido em uma experiência educativa em que o processo de construção do conhecimento está integrado às práticas vividas. Ensina-se pelas experiências proporcionadas, pelos problemas criados e pela ação desencadeada. Esse adolescente deixa de ser, nessa perspectiva, apenas um "aprendiz" do conteúdo. Ele é um ser humano que está desenvolvendo uma atividade e que, nesse processo está se apropriando de certo conhecimento cultural e se formando como sujeito cultural. ${ }^{15}$

Diante do exposto, pergunta-se: podem as oficinas de artes visuais contribuir para o resgate da autoestima e desenvolvimento de habilidades sociais de adolescentes em risco social?

Os objetivos foram oferecer oficinas de artes visuais para adolescentes, com ênfase na intervenção gru- 
pal e conhecer a percepção dos adolescentes sobre a experiência com as oficinas de artes, visando a criação de um espaço de troca de experiências, aproximação social e desenvolvimento de habilidades sociais.

\section{MÉTODO}

Cerca de 50 adolescentes estavam matriculados nas oficinas oferecidas pela ONG, por ocasião desta pesquisa. As oficinas oferecidas eram de artes visuais, computação, hip-hop, violão, capoeira e canto. Foram critérios de inclusão: adolescentes a partir dos 11 anos, que pudessem compreender o propósito do estudo e não tivessem nenhum comprometimento cognitivo que os limitassem a compreensão dos propósitos da pesquisa, que manifestassem seu desejo de participar deste, com a respectiva anuência de seus pais ou responsáveis.

Participaram deste estudo 18 (dezoito) adolescentes, cujos pais ou responsáveis assinaram o termo de Consentimento Livre e Esclarecido (TCLE). Dentre esses, 8 (oito) eram do sexo feminino e 10 (dez) do sexo masculino, com idade entre 11 e 15 anos.

O presente estudo foi aprovado pelo Comitê de Ética em Pesquisa da Universidade de Franca (protocolo $\left.n^{\circ} 634.883\right)$, respeitando-se todos os princípios e preceitos éticos de estudos com seres humanos, conforme dispostos na Resolução n 466/12 do Conselho Nacional de Saúde.

É um estudo qualitativo, que usou como método, a pesquisa participante, de cunho educativo e que buscou a participação dos adolescentes para a análise de sua própria realidade. A pesquisa participante possibilita a construção dialógica sobre a realidade social que se investiga, ou seja, o pesquisador é alguém que não somente intervém, mas "atua" no processo. ${ }^{16}$

Os adolescentes do presente estudo encontram-se em situação de vulnerabilidade/risco social de uma ONG, da cidade de Franca (SP), que se propõe, por meio de atividades educativas, combater a exclusão social. Esta ONG realiza atividades com adolescentes que vêm encaminhados por alguns equipamentos sociais, tais como o CRAS, o CREAS e o Conselho Tutelar.

O CRAS - Centro de Referência de Assistência Social é o sistema governamental responsável pelas famílias em situação de extrema pobreza e atua na organização e oferta de serviços da Proteção Social Básica, nas áreas de vulnerabilidade e risco social. O CREAS - Centro de Referência Especializado de Assistência Social configura-se como uma unidade pública e estatal, que oferta serviços especializados e continuados a famílias e indivíduos em situação de ameaça ou violação de direitos (violência física, psicológica, sexual, tráfico de pessoas, cumprimento de medidas socioeducativas em meio aberto, etc.). E o Conselho Tutelar foi criado com o Estatuto da Criança e do Adolescente (ECA) em 1990. É um órgão composto por cinco conselheiros escolhidos pela comunidade, que compõem o Sistema de Garantia de Direitos da Criança e do Adolescente. Tem a função de tomar providências em casos de ameaças ou violação dos direitos e é de responsabilidade da prefeitura. ${ }^{17}$

As oficinas de artes foram realizadas pela pesquisadora, com o auxílio de estagiários do curso de Artes Visuais da Universidade de Franca. Ocorreram uma vez por semana, sempre às quartas-feiras, no período das nove às onze horas da manhã e das três às cinco horas da tarde, totalizando 60 encontros, trinta por período.

Ao longo da pesquisa, foram anotadas, em um diário de campo, as observações relacionadas às oficinas, comentários e percepções dos adolescentes, bem como o registro de outras atividades como: reuniões, conversas informais com dirigentes e com o corpo técnico e administrativo. O conjunto das informações colhidas foi utilizado para desenvolver e enriquecer as análises e discussões relativas à pesquisa.

A programação das oficinas e seus conteúdos foram organizados de acordo com a demanda e o grau de interesse dos participantes. Foram diversificadas e sem foco especifico, com o objetivo de contribuir para que os participantes desenvolvessem as habilidades capazes de resultar em transformações.

As técnicas utilizadas durante as oficinas foram 1. Argila; 2. Desenho; 3. Colagem; 4. Monotipia; 5. Releitura; 6. Flipbook; 7. Isogravura; 8. Pintura de mural; 9. Desenho com Giz de cera; 10. Textura - Mosaico.

Este artigo traz recortes de algumas oficinas, cujos momentos relatam as atitudes iniciais dos adolescentes e o que foram capazes de construir ao longo dos 30 encontros.

\section{RESULTADOS}

No início, a participação não foi fácil, pois além das atitudes desafiadoras e provocativas dos adolescentes, existia uma falta de interesse na realização das atividades.

A falta de conhecimento prévio sobre arte, somada à falta de leitura e de hábitos culturais (frequência de visitação a museus, teatros, etc.), tornou necessária à introdução de noções básicas sobre arte, mas a curiosidade e a vontade de aprender do grupo, possibilitou que houvessem mudanças no comportamento, levando-os a assimilarem aspectos importantes da arte contemporânea em pouco tempo.

Uma estratégia que despertou o interesse do grupo em participar das oficinas, foi a criação de um portfólio das atividades que teria fotos dos momentos de produção de arte dos participantes e que este seria posteriormente disponibilizado para o acesso de todos do grupo. Os registros para este portfólio, foram construídos na composição de vários olhares: da pesquisadora, dos adolescentes e dos estagiários que foram acompanhando o processo das oficinas.

O planejamento das atividades foi desenvolvido de acordo com o interesse dos participantes, que consideraram que ler e escrever seria difícil, mas que desenhar e pintar seria ótimo. Uma das propostas foi proporcionar, aos participantes, compreender as três etapas do processo artístico da metodologia triangular de Ana Mae Barbosa: ${ }^{18}$ a produção (criação), apreciação (fruição) e a contextualização (reflexão). Buscou-se abrir um espaço para que pudessem falar sobre seus sonhos, sua cultura, sua realidade, com seu modo singular de se expressar por intermédio das artes.

Considerando os dados pessoais fornecidos pela psicóloga da Instituição como as personalidades dos participantes e suas necessidades, as atividades foram 
elaboradas de forma a serem mais rápidas e foram planejadas considerando também as características da realidade local e global conforme preconiza Amparo. ${ }^{19}$

A proposta da primeira oficina foi fazer o autorretrato; para isso foram apresentadas pinturas de autorretratos de alguns pintores consagrados, como Modigliani, Picasso, Frida Khalo, após terem sido relatadas suas biografias, principais curiosidades sobre estes artistas, como trabalhavam e principais técnicas. Os adolescentes interagiram fazendo perguntas e folheando os livros de artes, que eram aleatoriamente dispostos para que estes pudessem conhecer um pouco da produção destes artistas.

Inicialmente foram relutantes e não se mostraram muito afeitos à proposta. Prevalecia um discurso de incapacidade em desenhar, falta de proporcionalidade e beleza, como se nota em algumas falas.

(...) Nossa como você conseguiu fazer a boca. (P1, 12a, Fem.).

(...) Eu não consigo fazer o nariz. (P15, 11a, Masc.).

Entretanto, aos poucos se engajaram na produção de seus autorretratos passando a se identificarem mais com a produção deste, do que com o julgamento estético que pretensamente acreditavam serem alvos.

(...) A gente pode apresentar os trabalhos em algum lugar, pode mostrar nosso trabalho, aí os colegas da gente vem ver a gente. (P9, 13a, Masc.).

(...) Quero participar da exposição com muitos trabalhos. (P18, 13a, Masc.).

(...) Gostei de fazer meu o trabalho. (P15, 11a, Masc.).

Na oficina de argila, os alunos, de modo geral, ao amassarem a argila arremessavam com força contra a mesa, descarregando, no material, suas energias, tensões e raivas. Uma aluna descreve suas sensações e o que sentiu, modelando argila na primeira aula:

Tivemos o primeiro contato com a argila [...] Não tinha cheiro e foi muito bom, pudemos descarregar toda a nossa raiva e ódio batendo sobre a argila. (P12.M.14a.).

A técnica proporcionou descontração e interesse dos adolescentes, permitindo-Ihes darem suas opiniões sem receios.

Nossa, agora quando eu vejo um trabalho de arte, ou quando tem alguma coisa na escola, ou quando a gente sai com a psicóloga, eu sei que eu tenho que parar para olhar, para entender, pra ver se eu gosto ou não. (P16,11a, Masc.).

As colagens e suas construções estão entre as primeiras tentativas direcionadas para uma arte que esteja além da representação e decorrem de uma reviravolta da situação normal, do paradoxo de uma perspectiva "para fora" em vez de "para dentro". Assim, o objeto nasce da destruição do espaço.

Durante a oficina de "mosaico" foram distribuídos sobre a mesa vários materiais. Essa técnica foi prontamente aceita pelos adolescentes, trazendo descontração e comportamentos de solidariedade entre os participantes na divisão dos materiais. Os mosaicos apresentados pelos adolescentes retratam seu alto grau de satisfação com a proposta, associando-os a alegria, união dos participantes, lugar seguro para expressar as opiniões e a falta de julgamentos negativos.

É bom estar aqui; aprende muitas coisas e é ruim tem obrigação. (P.5,12a, Fem.).

É muito bom estar aqui...em casa eu faço quase tudo. Um monte de coisa, limpo a casa, cuido dos outros. (P6,15a, Fem.).

Procurou-se durante todas as oficinas, questionar e refletir sobre os assuntos abordados e vivenciados pelos participantes, pontuando as necessidades básicas de viver bem em sociedade.

Alguns participantes relataram sobre o ambiente em que estão inseridos, sobre as dificuldades que vivenciam.

(...) Estou de castigo, levei suspensão. Não posso sair! Só posso vir à ONG e cuidar dos meus irmãos. Vou tentar ser legal. É muito chato ser o irmão mais velho! (P14, 13a, Masc.).

(...) Hoje eu quase não vim, minha mãe não tinha dinheiro para me dar. (P1, 11a. Fem.).

Quando conseguiram executar o que foi proposto, eles se soltaram e passaram a perceber novas dimensões da vida, a vislumbrar novos horizontes, conversando entre si sobre a produção artística na escola. Compararam e fizeram planos sobre como as aulas na escola poderiam ser diferentes e melhores. Passaram a ter outras referências, concentrando-se mais nas atividades, fazendo leituras de seu cotidiano, transformando e buscando soluções. Falaram também sobre a família e anseios para o futuro.

(...) Meu pai mora em São Paulo, um dia ele vai me levar na praia. Vou poder conhecer outros lugares. (P5, 12a, Fem.).

As oficinas de pintura mural permitem a inserção do adolescente no espaço da ONG e seu reconhecimento como participante desta, pois essa técnica é realizada em um local mais visível, com maior compartilhamento do trabalho artístico e do material utilizado.

A valorização de sua produção em um espaço grande, sem críticas, sem julgamento, atua no reforço de sua autoestima. Os adolescentes têm a possibilidade de trazer elementos de seu cotidiano, de mostrar para os outros este cotidiano, favorecendo as relações pessoais e interpessoais. As atividades de artes mais solicitadas foram a pintura e o desenho, contrariando o senso comum que é a visão de artes como difícil, como hora de lazer, algo supérfluo, sendo ignorada como área de conhecimento.

Durante as oficinas, os adolescentes tiveram a oportunidade de fazer atividades criativas, aprender várias técnicas, ampliando seus conhecimentos no campo específico das artes, ao mesmo tempo em que passaram a valorizar suas atitudes. 


\section{DISCUS5ÃO}

Percebeu-se que a proposta do autorretrato foi significativa para os adolescentes, trazendo à tona emoções e sensações. Esta plasticidade do material proporcionou aos alunos o maior envolvimento na atividade. Ao pintar uma tela, uma folha ou até mesmo uma parede, o sujeito amplia sua relação com o mundo de forma espontânea, adquirindo uma sensibilidade e capacidade de lidar com outras expressões. ${ }^{20}$

A modelagem com argila revelou-se um importante aliado para descarregar energia, e lidar com as emoções, permitindo modelar sensações, sentimentos, pensamentos e esperanças. ${ }^{21}$

A arte como uma linguagem aguçadora dos sentidos, transmite significados que não podem ser transmitidos através de nenhum outro tipo de linguagem, tais como a discursiva e a científica. Para a autora, dentre as artes, as visuais, tendo a imagem como matéria-prima -, tornam possível a visualização de quem somos, onde estamos e como sentimos. ${ }^{22}$

A colagem é uma técnica de apreensão da realidade e sua expressão auxilia a vencer as barreiras iniciais do desenho e da pintura para quem não sabe ou não tem facilidade. Ela permite várias possibilidades para reflexão e contextualização. ${ }^{23} \mathrm{~A}$ arte a favor de ações em promoção da saúde, desdobra-se em uma infinidade de possibilidades que viabilizam que os temas da promoção da saúde sejam contemplados, sobretudo quando se trata de populações vulneráveis ou socialmente excluídas.

A escolha pelas artes visuais com adolescentes em situação de risco social, foi pensada a partir de constatações anteriores, pois que estes grupos não respondem afirmativamente a intervenções/pesquisas que adotam métodos 'tradicionais', seja pela faixa etária em que se encontram, seja pela situação de exclusão social ou minoria desprovida de voz.

Em trabalho realizado com população de rua, Matraca e Araújo ${ }^{24}$ utilizaram a arte da "palhaçaria" para dar voz à população excluída, valendo-se do registro de imagens e sons, filmagens e fotografias para a realização de um documentário. Conforme relataram os autores Um trabalho de diálogos com populações excluídas dificilmente pode transcorrer com instrumentos convencionais de pesquisa tais como questionários fechados, pranchetas e anotações (p. 164).

Os resultados desta pesquisa são semelhantes ao encontrados por Justa e Holanda, ${ }^{25}$ que embora tenham utilizado teatro como estratégia para trabalho com adolescentes em risco social, demonstraram que este foi capaz de provocar mudanças no posicionamento dos adolescentes frente a si mesmos e à sociedade, que passaram a ser mais participativos e conscientes e a demonstrar mais vontade e atitude para enfrentar a vida.

Em pesquisa realizada com idosos no município de Botucatu (SP), que utilizou a arte com a finalidade de facilitar a expressão de sentimentos, sensações e percepções, contribuindo para a saúde e bem estar em geral, a autora conclui sobre a necessidade de rever a formação profissional em saúde que possa entender a subjetividade do outro e como esta é importante para seu reestabelecimento ou mesmo cura e a formação deveria se pautar por modelos de assistência que reconheçam o ser humano como um ser total, tendo a arte importante contribuição para esta formação. ${ }^{26}$ Conforme Araújo, Câmara, Ximenes; ${ }^{27}$

Partindo dessas concepções, a saúde se configura como possibilidade de participação social, integrando a expressão criativa do sujeito no campo relacional. A criação artística promoveria a saúde do sujeito, haja vista que o retira de práticas automatizadas, vivenciadas no cotidiano, para a valorização de práticas criativas, inovadoras que apontam para a saúde.

Desta forma, a arte revela-se como uma estratégia importante que suscita discussões no campo da saúde, facilitando o fortalecimento das relações sociais e participativas dos sujeitos, o que contribui para o processo de construção da saúde das pessoas/comunidades, uma vez que, a arte, permite a expressão criativa, vinculação e contato, além de se inserir como uma forma de cuidado, além de retratar a realidade cotidiana, com seus anseios, necessidades, problemas e soluções. ${ }^{27}$

Com o intuito de aproximar os adolescentes de uma Unidade Básica de Saúde (UBS), em um município baiano, foi criado um programa "Adolescer com Arte", que desenvolve ações com o foco no protagonismo juvenil, por meio das artes, pois verificou-se que as palestras e outras forma tradicionais de transmissão de conhecimento não produziam efeitos necessários para que os jovens pudessem se vincular à UBS e terem acesso às informações sobre doenças sexualmente transmissíveis (DST), gravidez não planejada, violência, entre outros temas que apontam para vulnerabilidades tão facilmente associadas à esta fase do desenvolvimento humano. ${ }^{28}$

Foi possível observar que as oficinas de artes visuais realizadas em encontros grupais, foram importantes para a construção da identidade do adolescente, pois Ihes propiciou os meios para falarem de si e reconhecerem tantos seus medos como seus sonhos. Conclusão semelhante ao trabalho realizado por muitos outros autores aqui citados. ${ }^{10,11,13,19,24,25,27,28}$

\section{CONSIDERACÕES FINAIS}

A arte propicia uma relação mais consciente do adolescente no mundo e para o mundo, e contribui diretamente na formação de sujeitos críticos e criativos que possam, no futuro, atuar na transformação da sociedade. Durante as oficinas, que funcionaram como um laboratório, o conhecimento e as relações foram construídos em meio a erros e acertos, o que só foi possível devido ao ambiente seguro, que propiciou o surgimento de vínculos e trocas. Falavam de tudo, da vida, família, com ligação de cada parte com o todo de sua história, destacavam fatos sobre sua casa, seus sonhos, queriam ficar livres da escola.

As oficinas foram de fato "encontros", em que se procurou oportunizar as reflexões sobre aspectos relacionados à forma como compreendiam o mundo e como se percebiam a si mesmos.

A arte e seu encontro com a saúde possibilita construir conhecimentos que podem ser reproduzidos igualmente, em outros espaços e adequados a outros públicos.

As oficinas de artes visuais proporcionaram uma 
alternativa no atendimento aos adolescentes, permitindo a manifestação de subjetividade e produções de novas perspectivas, abrindo caminhos para intervenções que potencializam os fatores de proteção, promoção da saúde e minimizam os fatores de riscos presentes no contexto e na história dos adolescentes. Essa pesquisa mostrou a viabilidade da arte como um instrumento para ajudar no desenvolvimento das habilidades sociais, no empoderamento, na autoestima e, assim, auxiliar na transformação individual e social dos adolescentes.

\section{REFERÊNCIAS}

1. Organização Pan-Americana de Saúde - OPAS. Carta de Ottawa. Primeira Conferência Internacional sobre Promoção da Saúde, Ottawa, 2008.

2. Buss PM. Promoção da saúde e qualidade de vida. Ciênc saúde coletiva 2000;5(1)163-177. doi: 10.1590/S141381232000000100014.

3. Macalini ER. O ensino de artes nas ONG'S: fatores históricos que implementaram as parcerias entre setor público e privado. Revista Educação, Artes e Inclusão 2012;6(2).

4. Carvalho SR, Gastaldo D. Promoção à saúde e empoderamento: uma reflexão a partir das perspectivas crítico-social pós-estruturalista. Rev Ciênc Saúde Coletiva, Campinas 2008;13(Sup2). doi: 10.1590/S141381232008000900007.

5. Cedaro JJ, Boas LMSV, Martins RM. Adolescência e sexualidade: um estudo exploratório em uma escola de Porto Velho - RO. Rev Psicol Ciênc Prof 2012;32(2):320-389. doi: 10.1590/S1414-98932012000200005

6. Soares $C B$. Mais que uma etapa do ciclo vital: a adolescência como um construto social. In: Borges, A.L.V.; Fujimori, E. Enfermagem e saúde do adolescente na atenção básica, Barueri, 2009, p.3-19. Série Enfermagem ABEN-SP.

7. Unicef - Fundo Das Nações Unidas Para A Infância. O direito de ser adolescente: oportunidade para reduzir vulnerabilidades e superar desigualdades. Brasília: UNICEF, 2011.

8. Vieira NFC, Gubert FA. Promoção de saúde do adolescente e concepções do cuidado, pp. 1834. In: Silva RM, Catrib AMF. (Orgs.). Promoção de saúde na adolescência e concepções de cuidado. Ceará: EdUECE, 2014.

9. Outeiral JO. Adolescer: estudos sobre adolescência. Porto Alegre: Artes Médicas Sul, 1994.

10. Bretas JRS. Vulnerabilidade e adolescência. SOBEP 2010;10(2)

11. Farre AGM da C. Promoção da saúde do adolescente baseada na arte/educação e centrada na comunidade. [Tese]. Universidade Federal do Ceará. Fortaleza. 2014.

12. Coli J. O que é Artes. São Paulo: Brasiliense, 2004.

13. Araújo CM, Oliveira MCSL. Significações sobre desenvolvimento humano e adolescência em um projeto socioeducativo. Educ Rev 2010;26(3):169-193. doi: 10.1590/ S0102-46982010000300009.

14. Brasil. Secretaria de Educação Fundamental. Parâmetros curriculares nacionais: Artes. Brasília: MEC/SEF, 1997.

15. Barbosa AM. John Dewey e o ensino da arte no Brasil. São Paulo: Cortez, 2001a.

16. Brandão CR. Repensando a Pesquisa Participante. São Paulo: Brasiliense, 1985

17. Brasil. Portal Brasil. Cidadania e Justiça. 2011. Disponível em: http://www.brasil.gov.br/cidadania-e-justica/2011/10/centrode-referencia-especializado-de-assistencia-social-creas.

18. Barbosa AM. Teoria e prática da educação artística. São Paulo: Cultrix, 1986.

19. Amparo DM. Adolescentes e jovens em situação de risco psicossocial: redes de apoio social e fatores pessoais de proteção. Estud psicol, Campinas 2008;13(2):165-174. doi: 10.1590/S1413-294X2008000200009.

20. Santos AM, Fratari MHD. Artes visuais na educação infantil. [Tese]. Faculdade Católica de Uberlândia, Uberlândia, 2011.

21. Chiesa RF. O diálogo com o barro: o encontro com o criativo. São Paulo: Casa do Psicólogo, 2004

22. Barbosa AM. Arte, educação e reconstrução social. Insight Psicoterapia e Psicanálise. São Paulo 2001;11(121).

23. Martins LR. Colagem: investigações em torno de uma técnica moderna. ARS - Revista do programa de pós-graduação em artes visuais da ECA/USP - edição 10, 2007. doi: 10.1590/ S1678-53202007000200006.

24. Matraca MVC, Araújo-Jorge TC. Inovação nas práticas de promoção da saúde por meio da arte da palhaçaria: a dialogia do riso registrada em vídeo-documentários nas experiências de campo. RUA [online] 2011;2(17).

25. Justa FMC, Holanda ICLC. Teatro com adolescentes em risco social: práticas de promoção da saúde no contexto terapêutico ocupacional. Revista Terapia Ocupacional Univ São Paulo 2012;23(1)16-23. doi: 10.11606/issn.2238-6149. v23i1p16-23.

26. Vasques MCPCF. A interface da arte e do bem-estar na promoção da saúde na terceira idade. 2014. 133 f. [Tese] - Universidade Estadual Paulista Júlio de Mesquita Filho, Faculdade de Medicina de Botucatu, 2014. Disponível em: <http://hdl.handle.net/11449/124032>

27. Araújo SMM, Câmara CMF, Ximenes VM. Arte e saúde comunitária: contribuições para a compreensão do processo de desinstitucionalização. Rev Psicol Saúde, Campo Grande 2012;4(2)106-115. Disponível em: <http://pepsic.bvsalud. org/scielo.php?script $=$ sci $\quad$ arttext\&pid $=$ S2177-093X2012 $000200003 \& \mathrm{lng}=\mathrm{pt} \& \mathrm{nrm}=$ iso $>$.

28. Cícero LB, Santana CC, Carmo GCS, Carvalho RC. Adolescer com arte: um exemplo de protagonismo juvenil. Adolescência e Saúde 2015;12(Sup 1):65-69.

Como citar: BOLZANI, Berliete; TONELLO, Maria Georgina Marques; BITTAR, Cléria Maria Lobo. Oficinas de artes visuais: empoderamento e desenvolvimento de habilidades sociais para adolescentes em situação de risco social. Cinergis, Santa Cruz do Sul, v. 17, n. 3, set. 2016. ISSN 2177-4005. Disponível em: < https://online.unisc.br/seer/index.php/cinergis/article/ view/7759 >. Acesso em: 11 out. 2016. doi:http://dx.doi.org/10.17058/cinergis.v17i3.7759. 